\title{
THE POST-MORTEM EVALUATION OF GLUCOSE CONCENTRATION IN BLOOD AND ITS DIAGNOSTICAL VALUE

\author{
Gintarė Lukočiūtė ${ }^{1}$, Karolina Ginčiené ${ }^{2}$, Sigitas Chmieliauskas ${ }^{3}$, Sigitas Laima ${ }^{4}$, \\ Jurgita Stasiūniené ${ }^{5}$, Dmitrij Fomin ${ }^{6}$, Algimantas Jasulaitis ${ }^{7}$
}

\begin{abstract}
:
Introduction: Hyperglycemia is a consequence of uncontrolled diabetes and over a long period of time can lead to serious violations of the various systems of the body. In daily clinical practice, glucose level in blood and glycated hemoglobin are major and frequently used worldwide laboratory findings for the diagnosis of glucose metabolism disorders. In forensic medicine, the diagnostic value of post-mortem blood glucose levels is questionable because of its significant and rapid variation after death. Our research was aimed to analyse glucose concentration in blood after death and to estimate its diagnostic value.

Methods: Data analysis of the State Forensic Medicine Service (SFMS) of Vilnius region of sudden death cases was performed. 238 autopsy findings were analysed. A retrospective analysis was performed using the R commander program.

Results: The analysis included 238 individuals, 161 (67.6\%) were men and 77 (32.4\%) women. Mean age was $52.28 \pm 15.45$ yeras. Mean alcohol level in blood was $2.257 \pm 1.482 \mathrm{~g} / \mathrm{L}$. Mean post-mortem glucose concentration in blood was $6.716 \pm$ $5.800 \mathrm{mmol} / \mathrm{l}$. The lowest glucose concentration was $0.600 \mathrm{mmol} / \mathrm{l}$ and the highest $-33.300 \mathrm{mmol} / \mathrm{l}$. There were no significant glycemia level difference between men and women $(\mathrm{p}=0.279)$. In 6 cases, glucose concentrations were compared before and after death. The difference in blood glucose was insignificant $(\mathrm{p}=0.90)$. There was no strong correlation between ethyl alcohol and glucose concentration $(\mathrm{r}=0.037, \mathrm{p}=0.667)$. There was a weak correlation between age and blood glucose concentration $(\mathrm{r}=0.03, \mathrm{p}=0.639)$.

Conclusions: According to SFMS autopsy data, post-mortem glucose levels remain within the normal values. Evaluation of glucose after death remains a valuable diagnostic criterion for sudden death due to hyperglycaemia, when the hyperglycaemic episode is first and fatal to the subject.
\end{abstract}

UDC Classification: 616-008, DOI: 10.12955/cbup.v7.1452

Keywords: glucose, hyperglycaemia, post-mortem.

\section{Introduction}

Hyperglycemia is a consequence of uncontrolled diabetes and over a long period of time can lead to serious violations of the various systems of the body. According to the World Health Organization approximately 3.7 million deaths are caused by elevated blood glucose levels. To be more accurate, 1.5 million of these deaths are determined by diabetes and its complications, such as diabetic ketoacidosis, and another 2.2 million by cardiovascular system diseases and chronic kidney disease which is directly related to elevated blood glucose concentration. This emphasizes that high blood glucose is linked with a high proportion of all caused mortality not only deaths directly determined by diabetes mellitus (Roglic \& World Health Organization, 2016). Fatal diabetes mellitus complications can be hard to detect because of changing specific microscopic and macroscopic findings. The exact cause of death is determined only during autopsy (Palmiere, 2015).

In daily clinical practice, glucose level in blood and glycated hemoglobin are major and frequently used worldwide laboratory findings for the diagnosis of glucose metabolism disorders (Association, 2018). In forensic medicine, the diagnostic value of post-mortem blood glucose levels is questionable because of its significant and rapid variation after death (C. Hess, Wöllner, Musshoff, \& Madea, 2013). First of all, blood glucose metabolization proceeds in cells for a while after the termination of cardiovascular and respiratory organ systems. The setting of limited oxygen supply causes the onset

\footnotetext{
${ }^{1}$ Faculty of Medicine, Vilnius University, Vilnius, Lithuania, gintare.lukociute@ gmail.com

${ }^{2}$ The State Medicine Servise, Vilnius, Lithuania, karolina.ginciene@gmail.com

${ }^{3}$ Department of Pathology, Forensic Medicine and Pharmacology, Institute of Biomedical Sciences, Faculty of Medicine, Vilnius University, Vilnius, Lithuania, jurgitastasiuniene@yahoo.com

${ }^{4}$ Department of Pathology, Forensic Medicine and Pharmacology, Institute of Biomedical Sciences, Faculty of Medicine, Vilnius University, Vilnius, Lithuania, sigitas.laima@mf.vu.It

${ }^{5}$ Department of Pathology, Forensic Medicine and Pharmacology, Institute of Biomedical Sciences, Faculty of

Medicine, Vilnius University, Vilnius, Lithuania, jurgitastasiuniene@yahoo.com

${ }^{6}$ The State Medicine Service, Vilnius, Lithuania, dmitrij.fomin@vtmt.lt

${ }^{7}$ Department of Pathology, Forensic Medicine and Pharmacology, Institute of Biomedical Sciences, Faculty of

Medicine, Vilnius University, Vilnius, Lithuania, algimantas.jasulaitis@mf.vu.lt
} 
of anaerobic glycolysis. Rapid metabolisation of glucose during glycolysis is a reason for the significant and instant decrease of glycemia and increase of lactic acid concentration. One glucose molecule is metabolized into two lactate molecules during the pathway of anaerobic glycolysis after death. The decrease of glycaemia in the first hour after death is approximately $13 \mathrm{mg} / \mathrm{dl}$ whereas lactic acid level in blood increase $10-15 \mathrm{mg} / \mathrm{dl} / \mathrm{h}$ during the next 10 hours after the death (Holstein, Titze, $\&$ Hess, 2018). Moreover, due to neurohormones, such as adrenaline, noradrenaline and dopamine, produced during agonal reactions and/or cardiopulmonary resuscitation previous to death, the liver converts glycogen into glucose and large amounts of glucose are released into the bloodstream (Palmiere \& Mangin, 2012). Also, glucose concentration fluctuates in different parts of the body. It is higher in the right side of the heart due to glycogenolysis in the liver after death (Holstein et al., 2018). As we can see, the processes occurring in the human body before and after death can affect the main biochemical markers for diagnosing glucose metabolism disorders. In the realm of forensic medicine, it is challenging to verify deadly disorders related to elevated blood glucose. The aim of our research is to analyze glucose concentration in blood after death and to estimate its diagnostic value.

\section{Data and Methods}

Procedure

The study was conducted in the State Forensic Medicine Service (SFMS) of the Vilnius region in Lithuania in 2018. There were retrospectively selected and analysed 238 cases of sudden death who have had blood glucose levels detected during autopsy. The blood alcohol level is a routine test during every autopsy in the State Forensic Medicine Service. Because of that, blood alcohol levels of all these cases were recorded additionally in parallel with glucose levels. Samples were collected postmortem according to standard procedures. All autopsies were conducted by the same forensic team, headed by a single pathologist. The collected information was anonymous, only gender and age were recorded.

\section{Statistical analysis}

The statistical analysis was performed using the $\mathrm{R}$ commander program. The chosen significance level was $p<0.05$.

\section{Results}

The analysis included 238 individuals, 161 (67.6\%) were men and 77 (32.4\%) women. Mean age was $52.28 \pm 15.45$, median - 54. Of all individuals, the youngest was 2 years old and the oldest 88 years old. Men's mean age was $50.27 \pm 15.13$ while women's $56.45 \pm 15.35$. There was a statistically significant mean age difference between genders $(p=0.0041)$. Men and women mean age is illustrated in Figure 1.

Mean alcohol level in blood of all cases was $2.257 \pm 1.482 \mathrm{~g} / \mathrm{L}$, median $2.210 \mathrm{~g} / \mathrm{L}$. The lowest detected ethyl alcohol concentration was $0.130 \mathrm{~g} / \mathrm{L}$ and the highest was $6.320 \mathrm{~g} / \mathrm{L}$. Men's mean alcohol level in blood was $2.18 \pm 1.52 \mathrm{~g} / \mathrm{L}$, meanwhile women's was $2.41 \pm 1.39 \mathrm{~g} / \mathrm{L}$. There was statistically insignificant difference between genders $(\mathrm{p}=0.39)$. Comparison of the mean ethyl alcohol level in blood by gender are presented in Figure 2.

Mean post-mortem glucose concentration in blood of all cases was $6.716 \pm 5.800 \mathrm{mmol} / \mathrm{l}$, median 3.150. The lowest glucose concentration was $0.600 \mathrm{mmol} / \mathrm{l}$ and the highest was $33.300 \mathrm{mmol} / \mathrm{l}$. The glycemia level frequency in all of the cases is illustrated in Figure 3.

Men's mean post-mortem glucose concentration in blood was $6.51 \pm 5.45 \mathrm{mmol} / \mathrm{l}$, whilst the women's was $7.09 \pm 6.50 \mathrm{mmol} / \mathrm{l}$. There were no significant glycemia level difference between men and women $(p=0.279)$. Comparison of the mean post-mortem glucose concentration in blood by gender is presented in Figure 4.

In 6 cases, the glucose concentrations were compared before and after death. The difference in blood glucose level was insignificant $(\mathrm{p}=0.90)$.

Also, there was no strong correlation between ethyl alcohol and glucose concentration in blood $(\mathrm{r}=$ $0.037, \mathrm{p}=0.667)$. This indicates that ethanol concentration has no effect on blood glucose level.

Furthermore, there is a weak correlation between age and blood glucose concentration $(r=0.03, p=$ 0.639). It means that blood glucose levels do not depend on age. 


\section{Figure 1: Men and women mean age.}

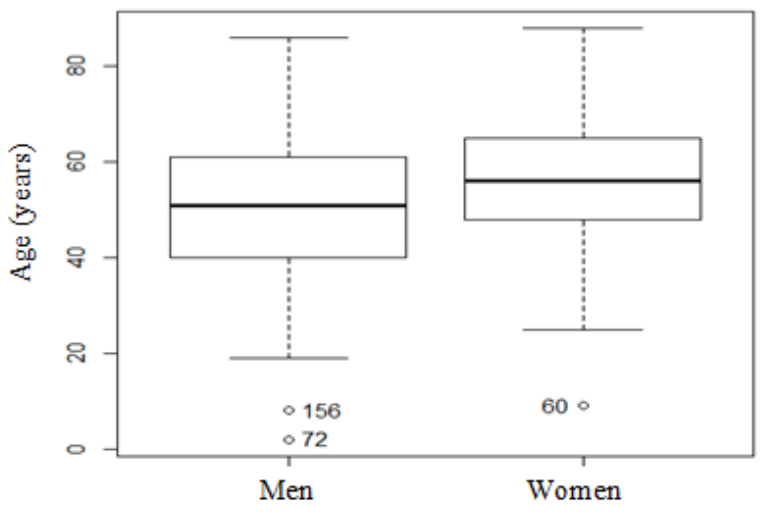

Blood glucose level (mmol/l)

\section{Source: Authors}

Figure 2: Comparison of the mean ethyl alcohol level in blood by gender.

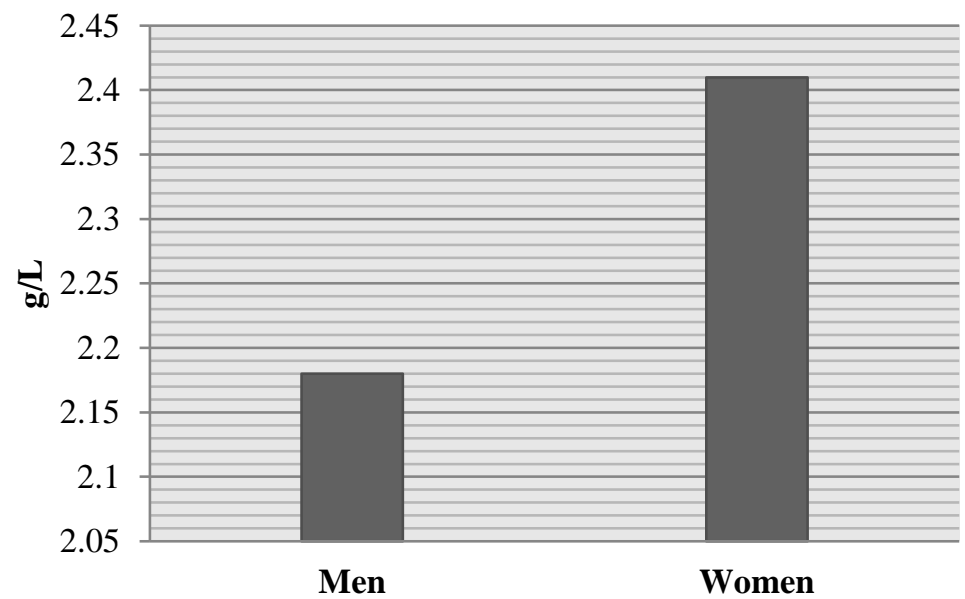

Source: Authors

Figure 3: Blood glucose level density

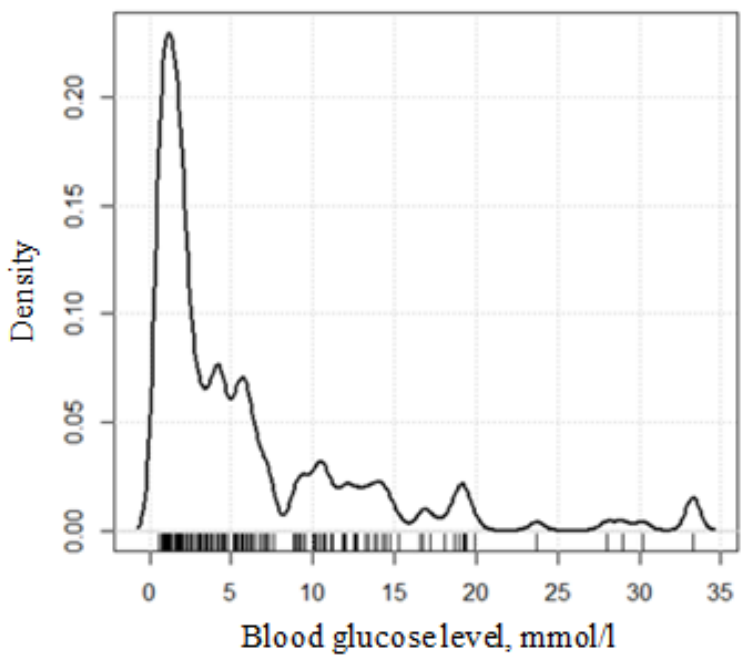

Source: Authors 


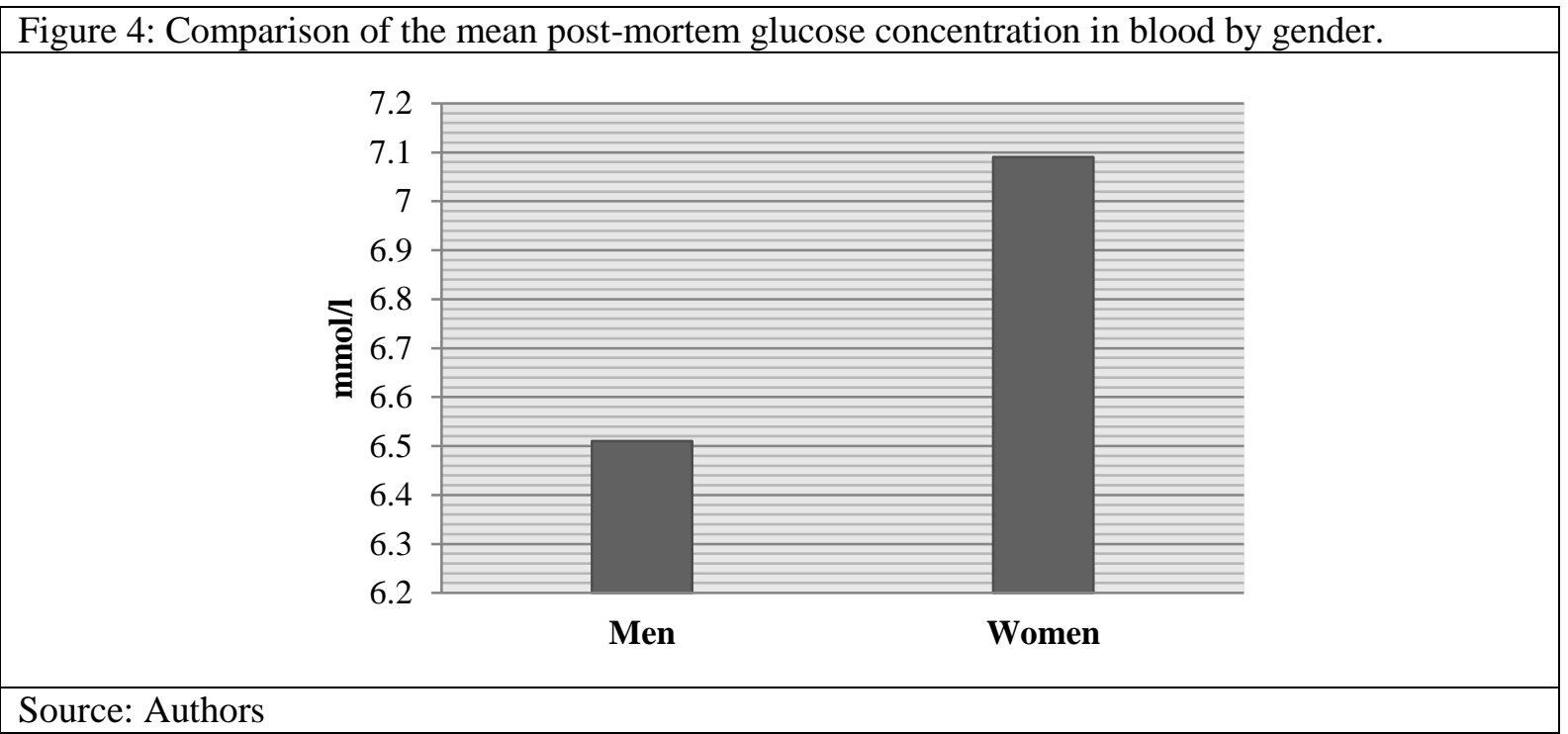

\section{Discussion}

The interpretation of post-mortem blood glucose levels is often difficult because of its variability after death. Unfortunately, references about the post-mortem evaluation of glucose concentration in blood and its diagnostical value only occasionally are found in the medical literature. One of the first reports concerning post-mortem blood glucose determination was published in 1940 and focused on the time after death at which the blood is analysed. It was emphasized that glucose level estimations must be made as soon as possible after death to have its high diagnostic validity to determine ante-mortem hyperglycemia otherwise the glycolysis will distort it (Hamilton-Paterson \& Johnson, 1940). According to the latest research data, blood glucose level alone does not have high diagnostic value (C. Hess, Stockhausen, Kernbach-Wighton, \& Madea, 2015; Holstein et al., 2018). In post-mortem analysis not only blood, but also vitreous fluid and cerebrospinal fluid are often used for glucose concentration examination. According to Cornelius Hess et al. glucose concentration in vitreous fluid correlate with glycaemia previous to death (Cornelius Hess, Musshoff, \& Madea, 2011; Musshoff, Hess, \& Madea, 2011). Moreover, estimation of HbA1c, fructosamine, or anhydroglucitol may provide useful data on the long-term glycemic control for individuals with diabetes (C. Hess et al., 2013; Lepik, Tõnisson, Kuudeberg, \& Väli, 2018; Walta, Keltanen, Lindroos, \& Sajantila, 2016).

Though it has been thought that the glucose concentration in blood doesn't have high diagnostic validity because of its broad variation after death there are some studies that suggest post-mortal blood glucose analysis can be a useful diagnostic tool. For example, Lundquist and Osterlin investigated glucose in blood and vitreous fluid from patients in whom the humour from the eye cavity had been removed. Those patients were divided into three groups: nondiabetic, then those with type 1 diabetes and those with type 2 diabetes. Glucose level in blood $(9.1 \pm 3.5 \mathrm{mmol} / \mathrm{L})$ was higher than in the vitreous humour $(3.5 \pm 1.8 \mathrm{mmol} / \mathrm{L})$ in all cases in the nondiabetic group. In diabetes type 1 and type 2 groups glucose in blood was also mostly higher compared to vitreous fluid with a couple of exceptions and glucose level both in vitreous humour (type 1 diabetes group $-9.4 \pm 3.3 \mathrm{mmol} / \mathrm{L}$, type $2-7.2 \pm 3.9 \mathrm{mmol} / \mathrm{L}$ ) and in blood (type 1 diabetes group $-15.4 \pm 4.2 \mathrm{mmol} / \mathrm{L}$, type $2-11.8 \pm$ $4.8 \mathrm{mmol} / \mathrm{L}$ ) was in general higher than in the nondiabetic group (Belsey \& Flanagan, 2016). Chen et al. thoroughly reviewed 672 forensic autopsies and analyzed glucose concentration tendencies in blood and various body fluids such as the vitreous humour, cerebrospinal and pericardial fluids. All these cases were classified as diabetic and nondiabetic according to hemoglobin A1C concentration (cut-off value of 6.5\%). Similar reasons of death were involved in both groups, except diabetic ketoacidosis was a predominant cause in the diabetic group, and malnourishment in the nondiabetic group. Glucose concentration in blood fluctuated within the normal range antemortem (70-109 $\mathrm{mg} / \mathrm{dL}$ ) in the majority of cases in the nondiabetic group, but elevated glucose level was noticed in electrocution, cerebrovascular disease, fatal alcohol abuse and sudden cardiac death caused by ischemic heart disease. Glycaemia was significantly higher in mortal ketoacidosis compared to other 
cases in the diabetic group. Additionally, elevated glucose level was detected in patients with chronic heart disease (Chen et al., 2015).

\section{Conclusions}

According to SFMS autopsy data, post-mortem glucose levels remain within the normal values. The difference in blood glucose levels found before and after death was insignificant. Evaluation of glucose after death remains a valuable diagnostic criterion for sudden death due to hyperglycaemia, when the hyperglycaemic episode is first and fatal to the subject.

\section{References}

Association, A. D. (2018). 2. Classification and Diagnosis of Diabetes: Standards of Medical Care in Diabetes-2018. Diabetes Care, 41(Supplement 1), S13-S27. https://doi.org/10.2337/dc18-S002

Belsey, S. L., \& Flanagan, R. J. (2016). Postmortem biochemistry: Current applications. Journal of Forensic and Legal Medicine, 41, 49-57. https://doi.org/10.1016/j.jflm.2016.04.011

Chen, J.-H., Michiue, T., Inamori-Kawamoto, O., Ikeda, S., Ishikawa, T., \& Maeda, H. (2015). Comprehensive investigation of postmortem glucose levels in blood and body fluids with regard to the cause of death in forensic autopsy cases. Legal Medicine (Tokyo, Japan), 17(6), 475-482. https://doi.org/10.1016/j.legalmed.2015.08.004

Hamilton-Paterson, J. L., \& Johnson, E. W. M. (1940). Post-mortem glycolysis. The Journal of Pathology and Bacteriology, 50(3), 473-482. https://doi.org/10.1002/path.1700500309

Hess, C., Stockhausen, S., Kernbach-Wighton, G., \& Madea, B. (2015). Death due to diabetic ketoacidosis: Induction by the consumption of synthetic cannabinoids? Forensic Science International, 257, e6-e11.

https://doi.org/10.1016/j.forsciint.2015.08.012

Hess, C., Wöllner, K., Musshoff, F., \& Madea, B. (2013). Detection of diabetic metabolism disorders post-mortem--forensic case reports on cause of death hyperglycaemia. Drug Testing and Analysis, 5(9 10), 795-801. https://doi.org/10.1002/dta.1479

Hess, Cornelius, Musshoff, F., \& Madea, B. (2011). Disorders of glucose metabolism-post mortem analyses in forensic cases: part I. International Journal of Legal Medicine, 125(2), 163-170. https://doi.org/10.1007/s00414-010-0509-6

Holstein, A., Titze, U., \& Hess, C. (2018). Postmortem Analysis of Vitreous Humor For Detection of Antemortem Disorders in Glucose Metabolism. An Old Method Revisited. Experimental and Clinical

Endocrinology \& Diabetes: Official Journal, German Society of Endocrinology [and] German Diabetes Association. https://doi.org/10.1055/a-0752-0028

Lepik, D., Tõnisson, M., Kuudeberg, A., \& Väli, M. (2018). Glycated haemoglobin (HbA1c) for postmortem diagnosis of diabetes. Forensic Sciences Research, 3(2), 170-177. https://doi.org/10.1080/20961790.2018.1452354

Musshoff, F., Hess, C., \& Madea, B. (2011). Disorders of glucose metabolism: post mortem analyses in forensic cases--part II. International Journal of Legal Medicine, 125(2), 171-180. https://doi.org/10.1007/s00414-010-0510-0

Palmiere, C. (2015). Postmortem diagnosis of diabetes mellitus and its complications. Croatian Medical Journal, 56(3), 181-193. https://doi.org/10.3325/cmj.2015.56.181

Palmiere, C., \& Mangin, P. (2012). Postmortem chemistry update part I. International Journal of Legal Medicine, 126(2), 187-198. https://doi.org/10.1007/s00414-011-0625-y

Roglic, G., \& World Health Organization (Eds.). (2016). Global report on diabetes. Geneva, Switzerland: World Health Organization.

Walta, A.-M., Keltanen, T., Lindroos, K., \& Sajantila, A. (2016). The usefulness of point-of-care (POC) tests in screening elevated glucose and ketone body levels postmortem. Forensic Science International, 266, 299-303.

https://doi.org/10.1016/j.forsciint.2016.06.003 